$\xi=\mathrm{\alpha}$

\title{
Using the analytic hierarchy process to prioritize alternative medicine: selecting the most suitable medicine for patients with diabetes
}

\author{
Mohammed A. Balubaid ${ }^{1} *$, Mohammed A. Basheikh ${ }^{2}$ \\ ${ }^{1}$ Department of Industrial Engineering, King Abdulaziz University, Jeddah, Saudi Arabia \\ ${ }^{2}$ Faculty of Medicine, King Abdulaziz University, Jeddah, Saudi Arabia \\ *Corresponding authorE-mail: mbalubaid@kau.edu.sa
}

\begin{abstract}
Diabetes mellitus (DM) is emerging as a major public health problem in Saudi Arabia and this disease affects the Middle East in general. The analytic hierarchy process (AHP) was performed to select the most appropriate oral hypoglycemic agent for use as a monotherapy among newly diagnosed patients with type 2 diabetes. Eight important criteria resulted from the hierarchy structure: side effects, chronic disease, background scientific evidence, age, weight, cost, education level, and gender. The involvement of these different factors reveals that treating diabetes is a multi-criteria decision making (MCDM) problem. Thus, AHP was used because it is one of the most common MCDM tools. This project developed a mathematical decision-making model that prioritizes the available medications for patients with diabetes in terms of the aforementioned criteria. Oral type 2 diabetes medications (metformin, pioglitazone, sitagliptin, and glimepiride) were ranked 1st, 2nd, 3rd and 4th, respectively; their weights were $48.42 \%, 24.47 \%, 13.61 \%$ and $13.50 \%$, respectively. Thus, metformin is recommended because it has the highest weight. Side effects were the most important factor affecting drug selection. The AHP provides an overall ranking to aid with final decisions. Unquestionably, the results of this project, or at least the proposed methodology, facilitate the decision-making process, which is important because it assists the decision maker in determining which oral drug to choose for newly diagnosed patients with diabetes.
\end{abstract}

Keywords: Analytic Hierarchy Process; Diabetes.

\section{Introduction}

Diabetes mellitus (DM) is a metabolic disorder with several etiologies. It is distinguished by chronic hyperglycemia with disturbances in carbohydrate, fat and protein metabolism. It consequences from defects in insulin secretion, insulin action (resistance), or both [1].

The development of DM management guidelines should be a healthcare priority because this disease is common, serious and costly. According to the Ad Hoc Diabetes Reporting Group, Saudi Arabia is a high-prevalence country $(18 \%-30 \%)$ [2]. This condition often leads to numerous complications and results in a large economic burden. Successful control is associated with reduced morbidity and mortality rates. Saudi Arabia has the second highest number of people with diabetes in the world, threatening approximately 4 million people in the Kingdom. In 1988, only $4 \%$ of the population of Saudi Arabia was diagnosed with diabetes [3].

This study attempts to help doctors choose the most appropriate treatment; this process is affected by several factors.

Numerous alternative medications are presently available to treat diabetes. Because of the numerous participants involved in this decision-making process, the selection of proper medication alternatives has become more difficult. Thus, we decided to select the four most commonly used diabetes medications: metformin, glimepiride, pioglitazone, and sitagliptin [4].

A selection of decision-making methods and tools are available to support healthcare and medical decision making. The current pa- per reviews and assesses the application of the analytic hierarchy process (AHP), to select the most suitable medicine for patients with diabetes.

\section{AHP background}

Developed by Saaty [5], [6], the AHP is one of several available multi-criteria decision-making (MCDM) analysis methods. This methodology is applied to structure, measure and synthesize.

This method allows the user to format problems in the form of a hierarchy or a set of integrated levels such as the goal, criteria, and alternatives. The main gain of the AHP is its use of pairwise comparisons to get a ratio scale of measurement. Ratio scales are a natural method of comparing alternatives, and they allow the calculation of both tangible and intangible factors.

The base of the AHP is composed of a set of axioms that define the scope of the problem setting [7]. The AHP is based on the clear mathematical structure of consistent matrices and the ability of their associated right eigenvectors to calculate exact or approximate weights [8-10]. The AHP compares criteria (or alternatives to a criterion) in a natural, pairwise fashion. In this process, the AHP uses a basic scale of absolute numbers, which has been proven in practice and validated by physical and decision-problem experiments. The basic scale captures individual preferences in terms of quantitative and qualitative attributes $[9,10]$. It converts individual preferences into ratio scale weights that can be shared into a linear additive weight (w[a]) for each alternative. The result 
can be used to compare and rank the alternatives and, hence, to assist the decision maker in their task. Given that these three basic steps are reasonable descriptors of how an individual naturally resolves a MCDM problem, the AHP is both a descriptive and prescriptive decision-making model. The AHP is perhaps the most widely used decision-making approach today. Its validity is based on the great number of actual applications in which AHP results were accepted and used by decision makers [11].

An important advantage of the AHP is that it allows for inconsistency in judgment. Other advantages and disadvantages of the AHP are extensively described and debated in the literature. For example, a series of articles in management science [12-16] compares the AHP with multi-attribute utility theory.

\section{The AHP in medicine}

Many research have discussed the use of the AHP across a broad range of health and medical decision-making applications. Hatcher [17] illustrated how the AHP can be included within a group decision support process (GDSP) and how the resulting system can be applied in several healthcare decision-making settings. Sloane [18] discussed the applicability of the AHP for medical and hospital decision support.

According to Liberatore, R.L. Nydick [19] evaluated 50 articles that addressed AHP applications in medicine. The greatest number of articles was related to project and technology evaluation and selection (14), followed by substantial activity in patient participation (9), therapy/treatment (8), and healthcare evaluation and policy (8).
The AHP has been used to evaluate and select medical treatments and therapies. This work did not involve the patient in the decision-making process. For example, Dolan [20] provided a detailed review of the theoretical foundations and methodologies of the AHP using the treatment of a dog bite wound as a motivating example. Dolan [20] applied the AHP to select an antibiotic regimen to treat a young woman hospitalized with acute pyelonephritis (kidney infection). The treatment alternatives included seven intravenous antibiotic regimens, and the criteria were maximizing the cure, minimizing the adverse effects (three categories), minimizing the cost, and minimizing resistance.

\section{Data collection}

A questionnaire was developed to collect the data. Four doctors completed the questionnaire. Next, the data was analyzed and the AHP is applied.

The AHP technique was performed to select the most appropriate oral hypoglycemic agent as a monotherapy for newly diagnosed patients with type 2 diabetes. The following eight criteria resulted from the hierarchy structure.

- $\quad$ Age (above 40 years old)

- Weight

- Gender

- Education level

- $\quad$ Background scientific evidence (for doctors)

- Chronic disease

- Cost

- $\quad$ Side effects (e.g., hypoglycemia)

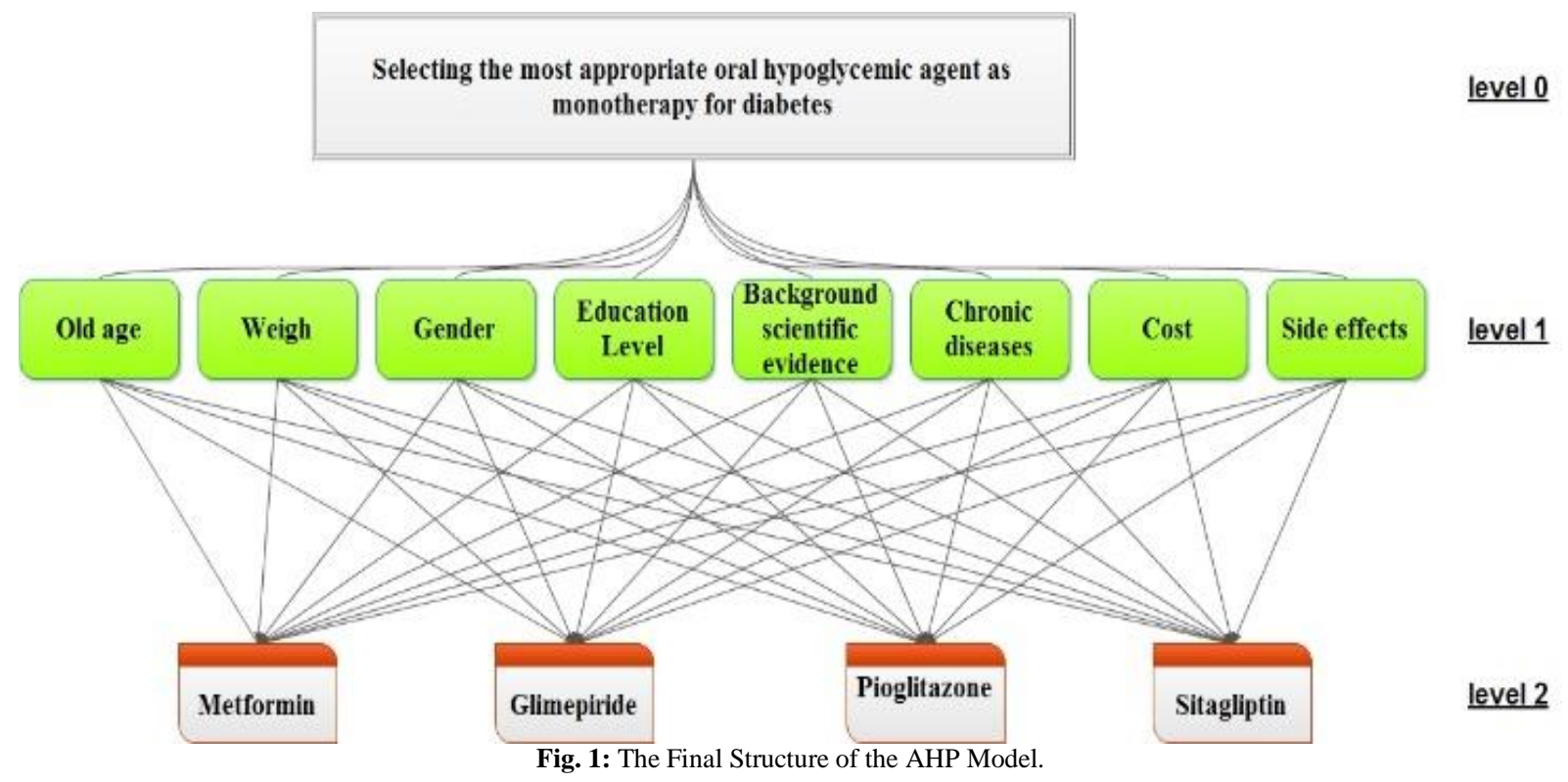

Fig 1 show the final structure of the AHP model. Two related questions exist for this model development, including all level 1 and 2 hierarchy questions.

Four doctors who served as internal medicine consultants at the Department of Medicine, King Abdulaziz University answered these questions. Table 1 shows the types of questions used for data collection.

\section{Model application}

In this section, we review in detail how we can solve MCDM problem concerning selecting the most appropriate oral hypoglycemic agent as a monotherapy for newly diagnosed patients with diabetes type 2 using the AHP.
Fig. 2 shows the final model after it was divided into several levels ranging from the Level 0 goal to the Level 2 alternatives.

Table 1: Types of Questions Used For Data Collection

\begin{tabular}{|c|c|c|c|}
\hline No. & Question & Category & $\begin{array}{l}\text { Possible } \\
\text { Answer }\end{array}$ \\
\hline 1 & $\begin{array}{l}\text { How much more important do you } \\
\text { think Factor } 1 \text { is than Factor } 2 ?\end{array}$ & $\begin{array}{l}\text { For the } \\
\text { criteria }\end{array}$ & $\begin{array}{l}\text { Scale } \\
\text { ranging } \\
\text { from } \\
1-9\end{array}$ \\
\hline 2 & $\begin{array}{l}\text { Regarding the specific criterion, how } \\
\text { much more do you think Alternative } 1 \\
\text { will contribute than Alternative } 2 ?\end{array}$ & $\begin{array}{l}\text { For the } \\
\text { alternatives }\end{array}$ & $\begin{array}{l}\text { Scale } \\
\text { ranging } \\
\text { from } \\
1-9\end{array}$ \\
\hline
\end{tabular}




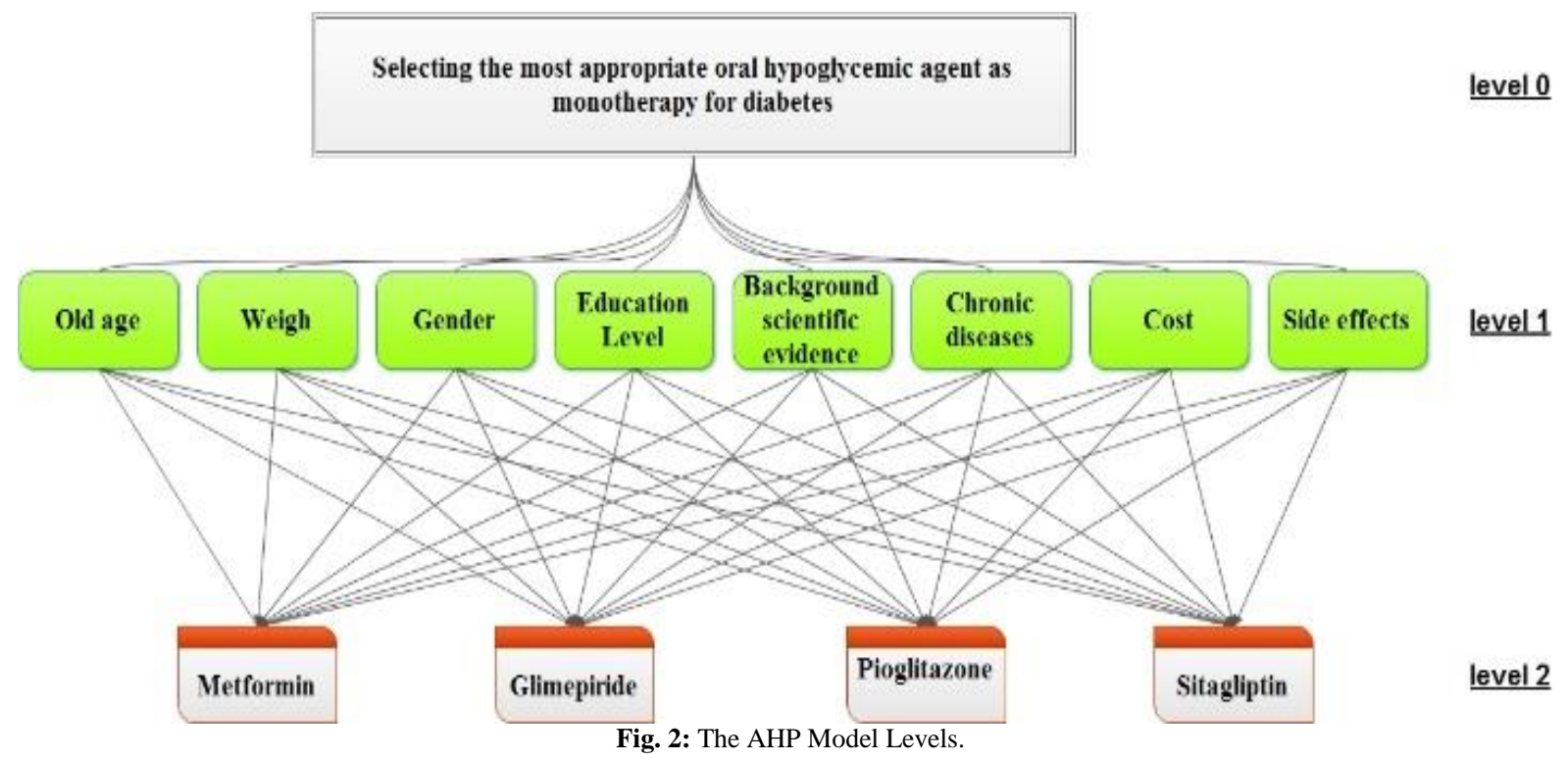

Model Levels: Level 0 represents the analysis goal used to select the most appropriate oral hypoglycemic agent as a monotherapy for newly diagnosed patients with type 2 diabetes. The second level (Level 1) involves following multi-criteria: age, weight, gender, education level, background scientific evidence, chronic disease, cost, and side effects.

The third level (Level 2) represents the alternatives (i.e., metformin, glimepiride, pioglitazone, and sitagliptin).

Determining how to calculate each level will be discussed in detail in the following next sections.

\section{Criteria Importance}

As shown in Fig. 2, Level 1 has one comparison matrix that corresponds to pairwise comparisons among 8 factors (i.e., age, weight, gender, education level, background scientific evidence, chronic disease, and side effects) with regard to the goal. Thus, the comparison matrix of Level 1 is $8 \times 8$.

Table 2 shows the criteria comparison matrix. Dr. 1 completed the upper triangular matrix as follows. We begin by comparing factors for age and weight. Dr. 1 strongly preferred age to weight when choosing a treatment; however, he rated age as equally significant to gender. Finally, he strongly preferred age to education level when choosing a treatment.

Table 2: The Level 1 Criteria Scores (Dr. 1)

\begin{tabular}{|c|c|c|c|c|c|c|c|c|}
\hline & AGE & WEIGHT & GENDER & EL & BSE & $\mathrm{CD}$ & COST & $\mathrm{SE}$ \\
\hline AGE & 1.00 & 7.00 & 1.00 & 7.00 & 0.13 & 1.00 & 4.00 & 0.20 \\
\hline WEIGHT & 0.14 & 1.00 & 1.00 & 0.33 & 1.00 & 0.20 & 1.00 & 0.17 \\
\hline GENDER & 1.00 & 1.00 & 1.00 & 1.00 & 0.13 & 0.20 & 1.00 & 0.20 \\
\hline BSE & 8.00 & 1.00 & 8.00 & 8.00 & 1.00 & 1.00 & 8.00 & 0.33 \\
\hline $\mathrm{CD}$ & 1.00 & 5.00 & 5.00 & 5.00 & 1.00 & 1.00 & 5.00 & 4.00 \\
\hline COST & 0.25 & 1.00 & 1.00 & 3.00 & 0.13 & 0.20 & 1.00 & 0.14 \\
\hline SE & 5.00 & 6.00 & 5.00 & 7.00 & 3.00 & 0.25 & 7.00 & 1.00 \\
\hline
\end{tabular}

EL: Education level

BSE: Background scientific evidence

CD: Chronic disease

SE: Side effects

In addition, Dr. 1 strongly preferred background scientific evidence to age, although rated age as equally significant compared with the chronic disease factor. He strongly preferred age to cost when choosing a treatment.

Dr. 1 considered weight as equally significant to gender but moderately preferred education level to weight when choosing a treatment. He rated the weight, background scientific evidence, and cost factors as equal, but he strongly preferred the chronic disease factor to the weight factor when choosing a treatment. Dr. 1 rated gender and education level as equal when choosing a treatment. He strongly preferred background scientific evidence to gender when choosing a treatment. Dr. 1 also strongly preferred the chronic disease factor to the gender factor but rated gender and cost as equal when choosing a treatment. He strongly preferred the background scientific evidence and chronic disease factors to education when choosing a treatment. However, Dr. 1 moderately preferred cost to education when choosing a treatment. Dr. 1 rated the background scientific evidence and chronic disease factors as equal, although he strongly preferred the former factor to cost when choosing a treatment. He strongly preferred the chronic disease factor to the cost factor, and strongly preferred the side effects factor to age when choosing a treatment. Furthermore, he strongly preferred the side effects factor to weight when choosing a treatment. He also strongly preferred the side effects factor to gender, and he strongly preferred the side effects factor to education level when choosing a treatment. He moderately preferred the side effects factor to the background scientific evidence factor but moderately to strongly preferred the chronic disease factor to the side effects factor when choosing a treatment. Finally, he strongly preferred the side effects factor when choosing a treatment.

The method of calculating the weights for each criterion within the same level is shown below.

Level 1:

Calculate the total for each column in the comparison matrix. 
Divide each summation score in the column to form a new matrix. Calculate the average summation of each raw score in the new matrix to provide the priority vector "the weights of each criterion". Table 3 shows the new matrix after the weights were calculated.

\section{Consistency ratio (CR)}

The method of calculating the CR for each criterion within the same level is shown below.

Level 1:

We multiplied the weight column using the Level 1 matrix shown in Table 2 .

We obtained the new matrix shown in Table 4.

Table 3: The New Level 1 Matrix after the Weights were Calculated (Dr. 1).

\begin{tabular}{|c|c|c|c|c|c|c|c|c|c|}
\hline & AGE & WEIGHT & GENDER & EL & BSE & $\mathrm{CD}$ & COST & SE & WEIGHTING \\
\hline AGE & 0.06 & 0.28 & 0.04 & 0.22 & 0.02 & 0.25 & 0.15 & 0.03 & 0.13 \\
\hline WEIGHT & 0.01 & 0.04 & 0.04 & 0.01 & 0.15 & 0.05 & 0.04 & 0.03 & 0.05 \\
\hline GENDER & 0.06 & 0.04 & 0.04 & 0.03 & 0.02 & 0.05 & 0.04 & 0.03 & 0.04 \\
\hline EL & 0.01 & 0.12 & 0.04 & 0.03 & 0.02 & 0.05 & 0.01 & 0.02 & 0.04 \\
\hline BSE & 0.48 & 0.04 & 0.35 & 0.25 & 0.15 & 0.25 & 0.29 & 0.05 & 0.23 \\
\hline $\mathrm{CD}$ & 0.06 & 0.20 & 0.22 & 0.15 & 0.15 & 0.25 & 0.18 & 0.65 & 0.23 \\
\hline COST & 0.02 & 0.04 & 0.04 & 0.09 & 0.02 & 0.05 & 0.04 & 0.02 & 0.04 \\
\hline SE & 0.30 & 0.24 & 0.22 & 0.22 & 0.46 & 0.06 & 0.26 & 0.16 & 0.24 \\
\hline
\end{tabular}

Table 4: The Result of Multiplying the Weight Column by the Level 1 Matrix

\begin{tabular}{|c|c|c|c|c|c|c|c|c|}
\hline & $\mathrm{AGE}$ & WEIGHT & GENDER & EL & BSE & $\mathrm{CD}$ & COST & SE \\
\hline $\mathrm{AGE}$ & 0.131 & 0.323 & 0.039 & 0.269 & 0.029 & 0.233 & 0.160 & 0.048 \\
\hline WEIGHT & 0.019 & 0.046 & 0.039 & 0.013 & 0.233 & 0.047 & 0.040 & 0.040 \\
\hline GENDER & 0.131 & 0.046 & 0.039 & 0.038 & 0.029 & 0.047 & 0.040 & 0.048 \\
\hline BSE & 1.045 & 0.046 & 0.312 & 0.307 & 0.233 & 0.233 & 0.320 & 0.080 \\
\hline $\mathrm{CD}$ & 0.131 & 0.231 & 0.195 & 0.192 & 0.233 & 0.233 & 0.200 & 0.959 \\
\hline COST & 0.033 & 0.046 & 0.039 & 0.115 & 0.029 & 0.047 & 0.040 & 0.034 \\
\hline SE & 0.653 & 0.277 & 0.195 & 0.269 & 0.700 & 0.058 & 0.280 & 0.240 \\
\hline
\end{tabular}

We calculated the sum of each row as shown in Table 5.

Table 5: The Crs of All Questionnaires

\begin{tabular}{ll}
\hline Sum & Sum/Weight \\
\hline 11.2523 & 9.422389699 \\
9.777815 & 10.32384872 \\
14.2527 & 10.69998553 \\
13.95566 & 9.325866381 \\
10.08592 & 11.04379513 \\
14.39608 & 10.19127439 \\
10.21705 & 9.58225627 \\
0.316722 & 11.14699159 \\
\hline
\end{tabular}

We divided the sum of the column by the weight of the column to find the average of that column $(\lambda \max )$ as shown in Table 6.

Table 6: The Crs for All Questionnaires

\begin{tabular}{lllll}
\hline & \multicolumn{5}{c}{ Dr. 1 } & Dr. 2 & Dr. 3 & Dr. 4 \\
\hline CR & 0.225 & 0.653 & 0.254 & 0.253 \\
\hline
\end{tabular}

We found the average of the new column in the last step.

We found the consistency index (CI) using the following formula:

$\mathrm{CI}=(\lambda \max -\mathrm{n}) /(\mathrm{n}-1)$, where $\mathrm{n}=8$ (number of factors) and $\lambda \max$ $=10.21705$ (the average of the summed column).

Finally, we applied this formula to find the consistency ratio (CR):

$\mathrm{CR}=\mathrm{I} / \mathrm{RI}$, where the random index $(\mathrm{RI})=1.41$.

Table 5 shows the sum of the each row in the matrix of Table 4 and the result of dividing the sum column by the weight column.

Where CI $=(\lambda \max -n) /(n-1)$,

$\mathrm{n}=$ the number of criteria, and

$\lambda \max =0.21705$ (the average of the sum column).

Then, $\mathrm{CI}=(10.21705-8) / 7=0.316721566$.

Finally, CR $=\mathrm{CI} / \mathrm{RI}=0.316721566 / 1.41=0.224625224$.

This method was used to calculate the CR, and we repeated this calculation for the other three questionnaires. The results are shown in Table 5.

Typically, the acceptable CR range is $10 \%$; based on our results, however, we decided to increase it to $25 \%$. Therefore, we eliminated the results of Dr. 2 because the CR was $65.3 \%$. Table 7 shows the final weights for all criteria for Drs. 1, 3, and 4
Table 7: The Average Weight for All Criteria for Drs. 1, 3, and 4

\begin{tabular}{lllll}
\hline & DR. 1 & DR. 3 & DR. 4 & WEIGHTS \\
\hline WGE & 0.1307 & 0.0472 & 0.1159 & 0.0979 \\
GEIGHT & 0.0461 & 0.0337 & 0.1661 & 0.0820 \\
ED & 0.0391 & 0.0246 & 0.0140 & 0.0259 \\
BSE & 0.0384 & 0.0882 & 0.0386 & 0.0551 \\
CD & 0.2333 & 0.1083 & 0.1490 & 0.1635 \\
COST & 0.2329 & 0.2483 & 0.2616 & 0.2476 \\
SE & 0.0400 & 0.1277 & 0.0475 & 0.0717 \\
SUM & 0.2397 & 0.3220 & 0.2074 & 0.2563 \\
& 1.0000 & 1.0000 & 1.0000 & 1.0000 \\
\hline
\end{tabular}

\section{Evaluation of alternatives}

Evaluation of Alternatives for Dr. 1: Our AHP model has 4 choice "alternatives" and 8 factors; each choice is connected to each factor. Therefore, we generally have eight $4 \times 4$ comparison matrices. As Table 8 shows, we began by examining age and comparing metformin with glimepiride. Dr. 1 strongly preferred metformin to glimepiride. Dr. 1 used the number 8, which corresponds to "very strongly to extremely strongly preferred". Thus, we conclude that metformin is preferred 8-fold over glimepiride.

Table 8: The Comparison Matrix for the Old Age Factor for Dr. 1

\begin{tabular}{lllll}
\hline Age & ME & GL & PI & SI \\
\hline ME & 1.00 & 8.00 & 5.00 & 5.00 \\
GL & 0.13 & 1.00 & 0.20 & 0.25 \\
PI & 0.20 & 5.00 & 1.00 & 1.00 \\
SI & 0.20 & 4.00 & 1.00 & 1.00 \\
SUM & 1.53 & 18.00 & 7.20 & 7.25 \\
\hline
\end{tabular}

ME: metformin

GL: glimepiride

PI: pioglitazone

SI: sitagliptin

Next, Dr. 1 compared metformin with pioglitazone. He preferred metformin to pioglitazone by 4 -fold.

Then, Dr. 1 compared metformin with sitagliptin and preferred the former by 4 -fold. 
In addition, Dr. 1 compared glimepiride with pioglitazone. He strongly preferred pioglitazone to glimepiride by 5 -fold.

Next, Dr. 1 compared glimepiride to sitagliptin, strongly preferring the latter to the former by 4 -fold.

Finally, Dr. 1 considered the remaining pairwise comparison, pioglitazone and sitagliptin. He rated pioglitazone as equal to sitagliptin (i.e., a score of 1 ).

The upper left-hand corner of the pairwise comparison matrix compares metformin with itself with regard to old age. When any factor is compared with itself, the evaluation scale must be 1, representing no difference in preference. Thus, we placed the number 1 in the upper left corner, which compares metformin with itself The same process is true when comparing glimepiride, pioglitazone, and sitagliptin with themselves. Each of these comparisons also received a score of 1 , which represents the drugs being equally preferred. For the remaining calculations, see Appendix X.

By following the same mathematical terminology of the criteria to obtain the final weights in Section 3.3.1, we were able to determine the score of each alternative by each criterion. Table 9 shows the comparison matrix of the scores for all of the alternatives after they had been calculated for the old age factor. For the remaining calculations for Dr. 1, see Appendix X. For the calculations for Drs. 3 and 4, see Appendices Y and Z, respectively.As Table 9 shows, the factor evaluation scores for metformin, glimepiride, pioglitazone, and sitagliptin were $0.621,0.050,0.171$, and 0.158 , respectively.

Table 9: The new matrix for the old age factor for Dr. 1

\begin{tabular}{llllll}
\multicolumn{7}{c}{ Table 9: The new matrix for the old age factor for Dr. 1 } \\
\hline Age & ME & GL & PI & SI & Scores \\
\hline ME & 0.6557 & 0.4444 & 0.6944 & 0.6897 & 0.6211 \\
GL & 0.0820 & 0.0556 & 0.0278 & 0.0345 & 0.0499 \\
PI & 0.1311 & 0.2778 & 0.1389 & 0.1379 & 0.1714 \\
SI & 0.1311 & 0.2222 & 0.1389 & 0.1379 & 0.1575 \\
\hline
\end{tabular}

\section{Evaluation of alternatives for all doctors}

As Table 10 shows, the average factor evaluation scores for metformin, glimepiride, pioglitazone, and sitagliptin were 0.604 , $0.1816,0.1130$, and 0.1012 , respectively. Thus, metformin is the most appropriate drug for older patients. As Table 11 shows, the average factor evaluation scores for metformin, glimepiride, pioglitazone, and sitagliptin were $0.6687,0.1096,0.1198$, and 0.1019 , respectively. Thus, metformin is the most appropriate drug regarding weight.

Table 10: The Evaluation of the Old Age Factor for Drs. 1, 3, and 4

\begin{tabular}{lllll}
\hline AGE & DR. 1 & DR. 3 & DR. 4 & AVG \\
\hline ME & 0.6211 & 0.6459 & 0.5458 & 0.6042 \\
GL & 0.0499 & 0.2058 & 0.2889 & 0.1816 \\
PI & 0.1714 & 0.0881 & 0.0794 & 0.1130 \\
SI & 0.1575 & 0.0602 & 0.0860 & 0.1012 \\
\hline
\end{tabular}

Table 11: The Evaluation of Weight for Drs. 1, 3, and 4

\begin{tabular}{lllll}
\hline WEIGHT & DR. 1 & DR. 3 & DR. 4 & AVG \\
\hline ME & 0.6044 & 0.7000 & 0.7018 & 0.6687 \\
GL & 0.0507 & 0.1000 & 0.1780 & 0.1096 \\
PI & 0.1992 & 0.1000 & 0.0601 & 0.1198 \\
SI & 0.1456 & 0.1000 & 0.0601 & 0.1019 \\
\hline
\end{tabular}

As Table 12 shows for Drs. 1, 3, and 4, the factor evaluation scores for metformin, glimepiride, pioglitazone, and sitagliptin were $0.5064,0.1376,0.1835$, and 0.1724 , respectively.

Table 12: The Evaluation of Gender for Drs. 1, 3, and 4

\begin{tabular}{lllll}
\multicolumn{4}{c}{ Table 12: The Evaluation of Gender for Drs. 1, 3, and 4 } \\
\hline GENDER & DR. 1 & DR. 3 & DR. 4 & AVG \\
\hline ME & 0.5692 & 0.7000 & 0.2500 & 0.5064 \\
GL & 0.0629 & 0.1000 & 0.2500 & 0.1376 \\
PI & 0.2006 & 0.1000 & 0.2500 & 0.1835 \\
SI & 0.1673 & 0.1000 & 0.2500 & 0.1724 \\
\hline
\end{tabular}

As Table 13 shows for Drs. 1, 3, and 4, the factor evaluation scores for metformin, glimepiride, pioglitazone, and sitagliptin were $0.5201,0.1337,0.1748$, and 0.1748 , respectively.

Table 13: The Evaluation for Education Level for Drs. 1, 3, and 4

\begin{tabular}{lllll}
\hline EDUCATION LEVEL & DR. 1 & DR. 3 & DR. 4 & AVG \\
\hline ME & 0.6437 & 0.6667 & 0.2500 & 0.5201 \\
GL & 0.0399 & 0.1111 & 0.2500 & 0.1337 \\
PI & 0.1634 & 0.1111 & 0.2500 & 0.1748 \\
SI & 0.1530 & 0.1111 & 0.2500 & 0.1714 \\
\hline
\end{tabular}

As Table 14 shows for Drs. 1, 3, and 4, the factor evaluation scores for metformin, glimepiride, pioglitazone, and sitagliptin were $0.5533,0.1362,0.2003$, and 0.1102 , respectively.

Table 14: The Evaluation for BSE for Drs. 1, 3, and 4

\begin{tabular}{lllll}
\hline B.S.E & DR. 1 & DR. 3 & DR. 4 & AVG \\
\hline ME & 0.4654 & 0.7000 & 0.4944 & 0.5533 \\
GL & 0.0443 & 0.1000 & 0.2642 & 0.1362 \\
PI & 0.3804 & 0.1000 & 0.1207 & 0.2003 \\
SI & 0.1100 & 0.1000 & 0.1207 & 0.1102 \\
\hline
\end{tabular}

As Table 15 shows, the factor evaluation scores for metformin, glimepiride, pioglitazone, and sitagliptin were 0.5747, 0.1307, 0.1825 , and 0.1121 , respectively.

Table 15: The Evaluation for Chronic Disease for Drs. 1, 3, and 4

\begin{tabular}{lllll} 
CHRONIC DE. & DR. 1 & DR. 3 & DR. 4 & AVG \\
\hline ME & 0.6039 & 0.4762 & 0.6440 & 0.5747 \\
GL & 0.0797 & 0.1230 & 0.1894 & 0.1307 \\
PI & 0.2222 & 0.2421 & 0.0833 & 0.1825 \\
SI & 0.0942 & 0.1587 & 0.0833 & 0.1121 \\
\hline
\end{tabular}

As Table 16 shows, the factor evaluation scores for metformin, glimepiride, pioglitazone, and sitagliptin were $0.6154,0.2317$, 0.0793 , and 0.0736 , respectively.

Table 16: The Evaluation for Cost for Drs. 1, 3, and 4

\begin{tabular}{lllll}
\multicolumn{5}{c}{ Table 16: The Evaluation for Cost for Drs. 1, 3, and 4 } \\
\hline COST & DR. 1 & DR. 3 & DR. 4 & AVG \\
\hline ME & 0.6842 & 0.5475 & 0.6146 & 0.6154 \\
GL & 0.1594 & 0.3060 & 0.2297 & 0.2317 \\
PI & 0.1016 & 0.1015 & 0.0347 & 0.0793 \\
SI & 0.0548 & 0.0450 & 0.1210 & 0.0736 \\
\hline
\end{tabular}

As Table 17 shows, the average factor evaluation scores for metformin, glimepiride, pioglitazone, and sitagliptin were 0.1946, $0.1039,0.4937$, and 0.2078 , respectively. Thus, pioglitazone is the most appropriate drug to treat side effects.

Table 17: The Evaluation for Side Effects for Drs. 1, 3, and 4

\begin{tabular}{lllll}
\hline SIDE EFFECT & DR. 1 & DR. 3 & DR. 4 & AVG \\
\hline ME & 0.4808 & 0.0591 & 0.0440 & 0.1946 \\
GL & 0.0661 & 0.1268 & 0.1189 & 0.1039 \\
PI & 0.2928 & 0.5893 & 0.5989 & 0.4937 \\
SI & 0.1603 & 0.2248 & 0.2382 & 0.2078 \\
\hline
\end{tabular}

Table 18 shows the factor evaluation for old age, and Table 17 shows the Random Index RI.

Table 18: The Factor Evaluation for Old Age

\begin{tabular}{lllll}
\hline Factor & ME & GL & PI & SI \\
\hline Age & 0.6211 & 0.0499 & 0.1714 & 0.1575 \\
\hline \multicolumn{5}{c}{ Table 19: The RI Number Functions } \\
\hline $\mathrm{n}$ & \multicolumn{5}{c}{ RI } \\
\hline 2 & 0.00 & \\
3 & 0.58 & \\
4 & & 0.9 & \\
5 & 1.12 & \\
6 & & 1.24 & \\
7 & & 1.32 & \\
8 & & 1.41 & \\
\hline
\end{tabular}




\section{Determining the consistency ratio}

To calculate the consistency ratio CR, we began by computing the weighted sum vector by multiplying the score of metformin times the first column of the original pairwise comparison matrix. We multiplied the second score by the second column and the third score times the third column of the original matrix of pairwise comparisons. Then, we summed these values over the following rows.

$\left[\begin{array}{c}(0.621 \times 1)+(0.0499 \times 8)+(0.1714 \times 5)+(0.1575 \times 5) \\ (0.6211 \times 0.13)+(0.049 \times 1)+(0.1714 \times 0.20)+(0.157 \times 0.25) \\ (0.6211 \times 0.20)+(0.0499 \times 5)+(0.1714 \times 1)+(0.1575 \times 1) \\ (0.6211 \times 0.20)+(0.0499 \times 5)+(0.1714 \times 1)+(0.1575 \times 1)\end{array}\right]$

Weight sum vector $=\left[\begin{array}{l}2.666 \\ 0.201 \\ 0.703 \\ 0.653\end{array}\right]$

The next step was to determine the consistency vector by dividing the weighted sum vector by the previously determined score values.

Consistency vector $=\left[\begin{array}{l}2.666 / 0.6211 \\ 0.201 / 0.0499 \\ 0.703 / 0.1714 \\ 0.653 / 0.1575\end{array}\right]=\left[\begin{array}{l}4.292 \\ 4.029 \\ 4.100 \\ 4.145\end{array}\right]$

\section{Computing $\lambda$ and the consistency index}

After calculating the consistency vector, we computed the values for two more terms ( $\lambda$ and the CI) before the final CR can be determined. The value for $\lambda$ is simply the average value of the consistency vector.

The formula for $\mathrm{CI}$ is as follows:

$\mathrm{CI}=\frac{\lambda \max -\mathrm{n}}{\mathrm{n}-1}$

Where $\mathrm{n}$ is the number of alternatives being compared. In our case, $\mathrm{n}=4$ for the four DM medications compared. The results of the calculations are as follows:

$\lambda=(4.292+4.029+4.100+4.145) / 4$

$=3.30772$, and

$\mathrm{CI}=\frac{\lambda \max -\mathrm{n}}{\mathrm{n}-1}=\frac{4.142-4}{3}$

$=.047$.

\section{Computing the consistency ratio}

Finally, we were able to compute the CR. The CR is equal to the CI divided by the RI, which is determined from a table. The RI is a direct function of the number of alternatives considered. This table was followed by the final calculation of the CR:

In our case,

$\mathrm{CR}=\frac{\mathrm{CI}}{\mathrm{RI}}=0.052$

The CR determines the consistency of our answers. The judgment of whether the decision is consistent is related to the $\mathrm{CR}$ value. If this value is greater than 0.1 , then we are less consistent; if it is less than 0.1 , then we are more consistent. In our project, however, we increased the value of the $\mathrm{CR}$ to 0.25 . As shown from the analysis, we are less consistent with our responses. Thus, our original assessments of the pairwise comparison matrix appear to be less consistent.
Table 20 displays the CR for all criteria for Drs. 1, 3, and 4; note that all of the values are less than the acceptance level of the decision maker's judgment, except for the CR associated public sector support. Therefore, we conclude that our original assessments of the pairwise comparison matrices for the remaining criteria are consistent, and the CRs that we computed support our observations.

Table 20: The Crs for All Criteria for Drs. 1, 3, and 4

\begin{tabular}{llll}
\hline CRITERIA & DR. 1 & DR. 3 & DR. 4 \\
\hline AGE & 0.052 & 0.21 & 0.055 \\
WEIGHT & 0.035 & 0.096 & 0.035 \\
GENDER & 0.053 & 0.000 & 0.053 \\
EL & 0.181 & 0.000 & 0.181 \\
BSE & 0.057 & 0.093 & 0.000 \\
CD & 0.112 & 0.077 & 0.094 \\
COST & 0.121 & 0.060 & 0.162 \\
SE & 0.132 & 0.240 & 0.170 \\
\hline
\end{tabular}

Although the calculations to compute the CR are fairly complex, they are an important step in using the AHP.

\section{Overall ranking for each doctor}

After conducting the pairwise comparisons for the criteria and alternatives as well as calculating the criteria weights and alternatives scores for each doctor, the next major step was to calculate the overall rank for each alternative for each doctor. The method for calculating the overall rank includes forming the overall score matrix by collecting scores by each criterion, for each medication, and for each doctor (here shown for Dr. 1; see Table 21).

Table 21: The Final Weights for All Criteria

\begin{tabular}{lllllllll}
\multicolumn{1}{c}{ Table 21: The Final Weights for All Criteria } \\
\hline CRI- & AG & WEIG & GEN- & \multirow{2}{*}{ EL } & BS & \multirow{2}{*}{ CD } & CO & \multirow{2}{*}{ SE } \\
TERIA & E & HT & DER & & E & \\
\hline WEIGH & 0.1 & \multirow{2}{*}{0.046} & \multirow{2}{*}{0.039} & 0.0 & 0.2 & 0.2 & \multirow{2}{*}{0.04} & 0.2 \\
$\mathrm{~T}$ & 31 & & & 38 & 33 & 33 & & 4 \\
\hline
\end{tabular}

Use the final weights for each criterion to determine the overall weighted score for each treatment. Table 22 shows the final weights for the criteria at all levels.

Table 22: The Overall Scores by Each Criterion for Each Medication (Dr.

\begin{tabular}{|c|c|c|c|c|c|c|c|c|}
\hline $\begin{array}{l}\text { Dr. } \\
1\end{array}$ & $\begin{array}{l}\mathrm{AG} \\
\mathrm{E}\end{array}$ & $\begin{array}{l}\text { WEIG } \\
\text { HT }\end{array}$ & $\begin{array}{l}\text { GEN- } \\
\text { DER }\end{array}$ & EL & $\begin{array}{l}\mathrm{BS} \\
\mathrm{E}\end{array}$ & $\mathrm{CD}$ & $\begin{array}{l}\text { COS } \\
\mathrm{T}\end{array}$ & SE \\
\hline $\mathrm{ME}$ & $\begin{array}{l}0.62 \\
1\end{array}$ & 0.604 & 0.569 & $\begin{array}{l}0.64 \\
4\end{array}$ & $\begin{array}{l}0.46 \\
5\end{array}$ & $\begin{array}{l}0.60 \\
4\end{array}$ & $\begin{array}{l}0.68 \\
4\end{array}$ & $\begin{array}{l}0.48 \\
1\end{array}$ \\
\hline GL & $\begin{array}{l}0.05 \\
0\end{array}$ & 0.051 & 0.063 & $\begin{array}{l}0.04 \\
0\end{array}$ & $\begin{array}{l}0.04 \\
4\end{array}$ & $\begin{array}{l}0.08 \\
0\end{array}$ & $\begin{array}{l}0.15 \\
9\end{array}$ & $\begin{array}{l}0.06 \\
6\end{array}$ \\
\hline PI & $\begin{array}{l}0.17 \\
1\end{array}$ & 0.199 & 0.201 & $\begin{array}{l}0.16 \\
3\end{array}$ & $\begin{array}{l}0.38 \\
0\end{array}$ & $\begin{array}{l}0.22 \\
2\end{array}$ & $\begin{array}{l}0.10 \\
2\end{array}$ & $\begin{array}{l}0.29 \\
3\end{array}$ \\
\hline SI & $\begin{array}{l}0.15 \\
8\end{array}$ & 0.146 & 0.167 & $\begin{array}{l}0.15 \\
3\end{array}$ & $\begin{array}{l}0.11 \\
0\end{array}$ & $\begin{array}{l}0.09 \\
4\end{array}$ & $\begin{array}{l}0.05 \\
5\end{array}$ & $\begin{array}{l}0.16 \\
0\end{array}$ \\
\hline
\end{tabular}

Then, multiply the scores in Table 21 by the weights in Table 22 . Table 23 shows the results.

Table 23: The Overall Rank for All Medications for Dr. 1

\begin{tabular}{ll}
\hline Diabetes Medication & Weighted score \\
\hline ME & 0.5477 \\
GL & 0.0640 \\
PI & 0.2604 \\
SI & 0.1279 \\
\hline
\end{tabular}

As shown in Table 23, metformin received the highest ranking, and Dr. 1 selected it as the most appropriate type 2 diabetes medication.

After conducting the previous steps for Drs. 1, 3, and 4, we averaged their weights (see Table 24). 
Table 24: The Average Weight for All Criteria Drs. 1, 3, and 4

\begin{tabular}{lllll}
\hline & DR. 1 & DR. 3 & DR. 4 & AVG \\
\hline AGE & 0.1307 & 0.0472 & 0.1159 & 0.0979 \\
WEIGHT & 0.0461 & 0.0337 & 0.1661 & 0.0820 \\
GENDER & 0.0391 & 0.0246 & 0.0140 & 0.0259 \\
EL & 0.0384 & 0.0882 & 0.0386 & 0.0551 \\
BSE & 0.2333 & 0.1083 & 0.1490 & 0.1635 \\
CD & 0.2329 & 0.2483 & 0.2616 & 0.2476 \\
COST & 0.0400 & 0.1277 & 0.0475 & 0.0717 \\
SE & 0.2397 & 0.3220 & 0.2074 & 0.2563 \\
\hline
\end{tabular}

Then, we found the overall scores by each criterion for each medication (Table 25)

Table 25: The Overall Scores against Each Criterion for Each Medication

\begin{tabular}{lllllllll}
\hline & AG & WEIG & GEN- & \multirow{2}{*}{ EL } & BSE & CD & COS & \multirow{2}{*}{ SE } \\
\hline M & 0.60 & \multirow{2}{*}{0.6890} & 0.5064 & 0.52 & 0.55 & 0.57 & 0.61 & 0.19 \\
E & 42 & & & 01 & 33 & 47 & 54 & 46 \\
G & 0.18 & \multirow{2}{*}{0.1030} & 0.1376 & 0.13 & 0.13 & 0.13 & 0.23 & 0.10 \\
L & 16 & & & 37 & 62 & 07 & 17 & 39 \\
PI & 0.11 & 0.1107 & 0.1835 & 0.17 & 0.20 & 0.18 & 0.07 & 0.49 \\
& 30 & & & 48 & 03 & 25 & 93 & 37 \\
SI & 0.10 & 0.0973 & 0.1724 & 0.17 & 0.11 & 0.11 & 0.07 & 0.20 \\
& 12 & & & 14 & 02 & 21 & 36 & 78 \\
\hline
\end{tabular}

Then, we multiplied the average weights in Table 24 by the scores in Table 25 . Table 26 shows the results.

Table 26: The Overall Rank for All Oral Diabetes Medication

\begin{tabular}{ll}
\hline Diabetes medication & Weighted score \\
\hline ME & 0.4842 \\
GL & 0.1350 \\
PI & 0.2447 \\
SI & 0.1361 \\
\hline
\end{tabular}

As shown in Table 26, metformin received the highest ranking, and it was selected as the most appropriate type 2 diabetes medication.

\section{Discussion}

As Table 27 shows, the internal medicine consultants ranked al criteria to select the most appropriate oral hypoglycemic agent as a monotherapy for patients with type 2 diabetes. Specifically, side effects, chronic disease, background scientific evidence, age, weight, cost, education level, and gender were ranked $1^{\text {st }}, 2^{\text {nd }}, 3^{\text {rd }}$ $4^{\text {th }}, 5^{\text {th }}, 6^{\text {th }}, 7^{\text {th }}$, and $8^{\text {th }}$, respectively.

Table 27: The Final Weights for All Criteria

\begin{tabular}{ll} 
& Table 27: The Final Weights for All Criteria \\
\hline Criteria & Weight \\
\hline SE & 0.256 \\
CD & 0.248 \\
BSE & 0.164 \\
AGE & 0.098 \\
WEIGHT & 0.082 \\
COST & 0.072 \\
EL & 0.055 \\
GENDER & 0.026 \\
\hline
\end{tabular}

The weights for side effects, chronic disease, background scientific evidence, age, weight, cost, education level, and gender were $25.6 \%, 24.8 \%, 16.4 \% 9.8 \%, 8.2 \%, 7.2 \%, 5.5 \%$, and $2.6 \%$, respectively (see Table 28).

Table 28: The Overall Scores by Each Criterion for Each Medication

\begin{tabular}{|c|c|c|c|c|c|c|c|c|c|}
\hline & $\begin{array}{l}\mathrm{AG} \\
\mathrm{E}\end{array}$ & $\begin{array}{l}\text { WEIG } \\
\text { HT }\end{array}$ & $\begin{array}{l}\text { GEN } \\
\text { DER }\end{array}$ & EL & BSE & CD & $\begin{array}{l}\text { CO } \\
\text { ST }\end{array}$ & SE & $\begin{array}{l}\text { OVER } \\
\text { ALL }\end{array}$ \\
\hline $\mathrm{M}$ & 0.60 & \multirow[b]{2}{*}{0.689} & 0.506 & 0.52 & 0.55 & 0.57 & 0.61 & 0.19 & \multirow[b]{2}{*}{0.4842} \\
\hline E & 42 & & 4 & 01 & 33 & 47 & 54 & 46 & \\
\hline G & 0.18 & \multirow{2}{*}{0.103} & 0.137 & 0.13 & 0.13 & 0.13 & 0.23 & 0.10 & \multirow{2}{*}{0.1350} \\
\hline $\mathrm{L}$ & 16 & & 6 & 37 & 62 & 07 & 17 & 39 & \\
\hline \multirow{2}{*}{ PI } & 0.11 & 0.110 & 0.183 & 0.17 & 0.20 & 0.18 & 0.07 & 0.49 & \multirow{2}{*}{0.2447} \\
\hline & 3 & 7 & 5 & 48 & 03 & 25 & 93 & 37 & \\
\hline \multirow{2}{*}{ SI } & 0.10 & 0.097 & 0.172 & 0.17 & 0.11 & 0.11 & 0.07 & 0.20 & \multirow{2}{*}{0.1361} \\
\hline & 12 & 3 & 4 & 14 & 02 & 21 & 36 & 78 & \\
\hline
\end{tabular}

The internal medicine consultants involved in our study ranked all oral diabetes medications in terms of their side effects. Specifically, pioglitazone, sitagliptin, metformin, and glimepiride were ranked $1^{\text {st }}, 2^{\text {nd }}, 3^{\text {rd }}$ and $4^{\text {th }}$, respectively; their weights were $49.37 \%$, $20.78 \%, 19.46 \%$ and $10.39 \%$, respectively.

All of the oral diabetes medications in our study were ranked in terms of chronic disease. Specifically, metformin, pioglitazone, glimepiride, sitagliptin were ranked $1 \mathrm{st}, 2 \mathrm{nd}, 3^{\text {rd }}$ and $4^{\text {th }}$, respectively; their weights were $57.47 \%, 18.25 \%, 13.07 \%$ and $11.21 \%$, respectively.

All of the oral diabetes medications in this study were ranked in terms of background scientific evidence. Metformin, pioglitazone, glimepiride, and sitagliptin were ranked $1^{\text {st }}, 2^{\text {nd }}, 3^{\text {rd }}$ and $4^{\text {th }}$, respectively; their weights were $55.33 \%, 20.03 \%, 13.62 \%$ and $11.02 \%$, respectively.

All of the oral diabetes medications in our study were ranked in terms of age. Specifically, metformin, glimepiride, pioglitazone, and sitagliptin were ranked $1^{\text {st }}, 2^{\text {nd }}, 3^{\text {rd }}$ and $4^{\text {th }}$, respectively; their weights were $60.42 \%, 18.16 \%, 11.30 \%$ and $10.12 \%$, respectively. All of the oral diabetes medications in our study were ranked in terms of weight. Specifically, metformin, pioglitazone, glimepiride, and sitagliptin were ranked $1^{\text {st }}, 2^{\text {nd }}, 3^{\text {rd }}$ and $4^{\text {th }}$, respectively; their weights were $68.90 \%, 11.07 \%, 10.30 \%$ and $9.73 \%$, respectively.

All of the oral diabetes medications in our study were ranked in terms of cost. Specifically, metformin, glimepiride, pioglitazone, and sitagliptin were ranked $1^{\text {st }}, 2^{\text {nd }}, 3^{\text {rd }}$ and $4^{\text {th }}$, respectively; their weights were $61.54 \%, 23.17 \%, 7.93 \%$ and $7.36 \%$, respectively.

All of the oral diabetes medications in our study were ranked in terms of education level. Specifically, metformin, pioglitazone, sitagliptin, and glimepiride were ranked $1^{\text {st }}, 2^{\text {nd }}, 3^{\text {rd }}$ and $4^{\text {th }}$, respectively; their weights were $52.01 \%, 17.48 \%, 17.14 \%$ and $13.37 \%$, respectively.

All of the oral diabetes medications in our study were ranked in terms of gender. Specifically, metformin, pioglitazone, sitagliptin, and glimepiride were ranked $1^{\text {st }}, 2^{\text {nd }}, 3^{\text {rd }}$ and $4^{\text {th }}$, respectively; their weights were $50.64 \%, 18.35 \%, 17.24 \%$ and $13.76 \%$, respectively.

\section{Recommendations}

Table 28 shows the overall ranking of oral type 2 diabetes medications. This table shows that metformin, pioglitazone, sitagliptin, and glimepiride were ranked $1^{\text {st }}, 2^{\text {nd }}, 3^{\text {rd }}$ and $4^{\text {th }}$, respectively; specifically, their weights were $48.42 \%, 24.47 \%, 13.61 \%$ and $13.50 \%$, respectively. Therefore, metformin is recommended because it has the highest weight.

Based on the overall weight associated with the criteria, the most important factor that affected the selection of the most appropriate diabetes medications was the side effects. Thus, we recommend that doctors focus on that factor.

\section{Conclusions}

As mentioned above, we assume that decision makers involved with diabetes treatment will use the outcome of this project. In conclusion, this project developed a mathematical decisionmaking model that prioritizes available oral medications for patients with diabetes in terms of eight criteria: side effects, chronic disease, background scientific evidence, age, weight, cost, education level, and gender. The involvement of different criteria reveals that the issue can be considered as an MCDM problem. Thus, the AHP should be used because it is one of the most common MCDM tools.

The AHP provides an overall ranking that can be used to make a final decision. Undoubtedly, the results of this project (or at least the proposed methodology) facilitate the decision-making process, which is important because it assists decision makers in choosing the most effective oral type 2 diabetes treatment. 


\section{References}

[1] L. Dean, J. McEntyre, editors, National Center for Biotechnology Information, The Genetic Landscape of Diabetes, NCBI, Bethesda MD, 2004

[2] K. Alqurashi, K.S. Aljabri, S.A. Bokhari, Prevalence of diabetes mellitus in a Saudi community, Annals of Saudi Medicine 31 (2011) 19-23. http://dx.doi.org/10.4103/0256-4947.75773.

[3] M.M. Al-nozha, M.A. Al-maatouq, Y.Y. Al-mazrou, S.S. Al-Harthi, M.R. Arafah, Diabetes mellitus in Saudi Arabia, Saudi Medical Journal 25 (2004) 1603-1610.

[4] R. Sicree, J. Shaw, P. Baker, (2010), the global burden: diabetes and impaired glucose tolerance. http://www.idf.org/sites/default/files/The_Global_Burden.pdf. Accessed 4 May, 2014.

[5] T.L. Saaty, A scaling method for priorities in hierarchical structures, Journal of Mathematical Psychology 15 (1977) 234-281. http://dx.doi.org/10.1016/0022-2496(77)90033-5.

[6] T.L. Saaty, the Analytic Hierarchy Process, RWS Publications, Pittsburgh, PA, 1996.

[7] T.L. Saaty, Axiomatic foundation of the analytic hierarchy process, Management $\quad$ Science $\quad 32 \quad$ (1986) 841-855 http://dx.doi.org/10.1287/mnsc.32.7.841.

[8] B.G. Mirkin, Group Choice, John Wiley \& Sons, New York, 1979.

[9] T.L. Saaty, the Analytic Hierarchy Process, McGraw-Hill Book Co., New York, 1980

[10] T.L. Saaty, How to make a decision: the analytic hierarchy process, Interfaces 24 (1994) 19-43. http://dx.doi.org/10.1287/inte.24.6.19.

[11] T.L. Saaty, Fundamentals of Decision Making, RWS Publications Pittsburgh, PA, 1994.

[12] J.S. Dyer, Remarks on the analytic hierarchy process, Management $\begin{array}{llll}\text { Science } & 36 & \text { (1990) 249-258. }\end{array}$ http://dx.doi.org/10.1287/mnsc.36.3.249.

[13] J.S. Dyer, A clarification of 'remarks on the analytic hierarchy process', Management Science $36 \quad$ (1990) 274-275. http://dx.doi.org/10.1287/mnsc.36.3.274.

[14] P.T. Harker, L.G. Vargas, Reply to 'remarks on the analytic hierarchy process' by J. S. Dyer, Management Science 36 (1990) 269 273. http://dx.doi.org/10.1287/mnsc.36.3.269.

[15] T.L. Saaty, An exposition of the AHP in reply to the paper 'remarks on the analytic hierarchy process', Management Science 36 (1990) 259-268. http://dx.doi.org/10.1287/mnsc.36.3.259.

[16] R.L. Winkler, Decision modeling and rational choice: AHP and utility theory, Management Science 36 (1990) 247-248. http://dx.doi.org/10.1287/mnsc.36.3.247.

[17] M. Hatcher, Voting and priorities in health care decision making, portrayed through a group decision support system, using analytic hierarchy process, Journal of Medical Systems 18 (1994) 267-288. http://dx.doi.org/10.1007/BF00996606.

[18] E.B. Sloane, M.J. Liberatore, R.L. Nydick, Medical decision support using the analytic hierarchy process, Journal of Healthcare Information Management 16 (2002) 38-43.

[19] M.J. Liberatore, R.L. Nydick, The analytic hierarchy process in medical and health care decision making: A literature review, European Journal of Operational Research 189 (2008) 194-207. http://dx.doi.org/10.1016/j.ejor.2007.05.001.

[20] J.G. Dolan, Medical decision making using the analytic hierarchy process: choice of initial antimicrobial therapy for acute pyelonephritis, Medical Decision Making 9 (1989) 51-56. http://dx.doi.org/10.1177/0272989X8900900109. 